\title{
Catechin attenuates complete freund's adjuvant induced rheumatoid arthritis: role of histidine decarboxylase
}

\begin{abstract}
Background: Arthritis is a joint disorder that involves inflammation and immune response in joints due to release of various inflammatory mediators.

Objective: The objective of present study was to investigate anti-arthritis activity of catechin on complete Freund's adjuvant induced arthritis models in rats.

Materials and methods: Rheumatoid arthritis was induced by sub plantar injection of the left hind paw with $0.1 \mathrm{ml}$ of complete Freund's adjuvant. Catechin was given orally once a day from day 1 to day 21 at the dose of $100 \mathrm{mg} / \mathrm{kg}$, p.o. and after which physical parameters like arthritic index, paw edema, paw thickness, splenomegaly and thymus index, biochemical and hematological parameters like C-reactive protein, serum rheumatoid factor, erythrocyte sedimentation rate and $\%$ hemoglobin and histopathology of ankle joints were carried out.

Results: Treatment of catechin to freund's adjuvant induced arthritis showed significant improvement in physical parameters like arthritic index, paw edema, paw thickness, splenomegaly and thymus index as well as reduction of inflammatory markers like C-reactive protein, serum rheumatoid factor, erythrocyte sedimentation rate and hemoglobin $\%$ as compared to disease control group. Furthermore, in the disease control group protective effect of catechin was observed in hyperplasia of synovium, pannus formation and destruction of the joint space.
\end{abstract}

Conclusion: From the present study we can conclude that catechin exhibited ameliorative effect by acting on immune system in experimental models of adjuvant induced arthritis.

Keywords: arthritis, catechin, complete freund's adjuvant, inflammation, histamine
Volume II Issue 3 - 2018

\author{
Snehal S Patel,' Vinit D Patel ${ }^{2}$ \\ 'Department of Pharmacology, Nirma University, India \\ 2 Medip Academy, SG Highway, India
}

Correspondence: Snehal S Patel, Department of Pharmacology, Institute of Pharmacy, Nirma University, Ahmedabad, Gujarat, 382 48I, India, Tel +9107927600686, Email snehalpharma53@gmail.com

Received: July 31, 2017 | Published: June 20, 2018

\section{Introduction}

Rheumatoid arthritis (RA) is a chronic inflammatory disease characterized by fibroblastic proliferation, infiltration of the synovial lining by inflammatory cells which leads to release of inflammatory mediators such as cytokines, histamine, leukotriene resulting in bone and joint destruction., ${ }^{1,2} \mathrm{RA}$ is the most common systematic autoimmune disease, affecting $1-1.5 \%$ of the population worldwide. However, current therapies for rheumatoid arthritis involve analgesics, corticosteroids, NSAIDS. Despite availability of wide range of drugs, relief offered by them is short lived, symptomatic and having lots of side effects. Hence it is required to identify effective and safe remedies for treatment of rheumatoid arthritis.

The plants are a rich reservoir of potential leads for drug discovery against various disorders. Almost half of the useful drugs today used for various disorders are derived from natural sources. Only less than two percent of all the plants available on the earth have been subjected to pharmacological investigations. In search of compounds that may be beneficial in rheumatoid arthritis, we have explored the possibility of polyphenolic compounds like catechin to have such potential. Catechin (3', 3', 4',5,7-flavanpentol) is a natural plant secondary metabolite has been reported have various bioregulatory activities, such as cytoprotective, antiparkinson's, anticancer, antidiabetic, antialzheimer, cerebroprotective, hepatoprotective, antihyperlipidemic, antifungal, anthelmentic, antipyretic, antiatherosclerotic effects. ${ }^{3-5}$ Catechin presents in various medicinal plants has been reported have antiallergic, anti-inflammatory as well as have beneficial effects in Type I and IV allergic reactions. ${ }^{6,7}$ Catechin present in extracts of leaves of Camellia sinensis L. are reported to produce the inhibitory effects on the release of histamine from the mast cells would partly contribute to the anti-allergic and anti-inflammatory effect. ${ }^{89}$ It is also reported that catechin produce inhibition of immune response mediated by sensitized lymphocytes, early and predominant mononuclear cell infiltration which leads to inflammation. ${ }^{8}$ Thus, from all these previous reports we can hypothesized that catechin may have beneficial role in treatment of rheumatoid arthritis.

\section{Materials and methods}

\section{Drugs and chemicals}

The catechin is procured from Sigma Aldrich Pvt. Ltd., India. Complete Freund's adjuvant was purchased from M. P. Biomedicals, France. Serum rheumatoid factor, C-reative protein kits were purchased (Lab care diagnostics Pvt Ltd., Ahmadabad, India). Other chemicals were of analytical grade.

\section{Experimental animals}

Animal experimental protocols were reviewed and approved by the Institutional Animal Ethics Committee and protocol number was IPS/PCOL/CONS11-12/2001, IP/PCOL/MPH13-1/009. Animals were procured from Cadila pharmaceuticals Ltd., Dholka, 
Ahmadabad. Animals were housed in the animal facilities of Nirma University, Ahmadabad under controlled conditions of temperature $23 \pm 2^{\circ} \mathrm{C}$, relative humidity $55 \pm 5 \%$, and photo-schedule $(12 \mathrm{~h}$ light and $12 \mathrm{~h}$ dark).

\section{Experimental protocol}

To evaluate the histidine decarboxylase inhibitory activity of catechin Wistar rats were divided into four groups six animals each: normal control group, normal treated with catechin $(100 \mathrm{mg}$ / $\mathrm{kg})$, catechin $(50 \mathrm{mg} / \mathrm{kg})$, catechin $(25 \mathrm{mg} / \mathrm{kg})$. Fourteen days after treatment compound $48 / 80$ was administered $0.75 \mathrm{mg} / \mathrm{kg}$, i.v. and lethality in all groups were determined after four hours of compound 48/80 administration and blood histamine content were determined by flurometric assay. Estimation of histidine decarboxylase was carried out from stomach by method described by Aures et al. Stomach was homogenized, centrifuged at $1500 \times \mathrm{g}$ and supernatant obtained as enzyme solution was incubated with $0.25 \mathrm{mmol}$ histidine for $4 \mathrm{hr}$ at $37^{\circ} \mathrm{C}$. The enzyme reaction was terminated using $0.8 \mathrm{~N}$ ice cold perchloric acid followed by centrifugation. Histamine was then extracted into $5 \mathrm{ml}$ isoamyl alcohol by shaking for 10minutes. After centrifugation, the supernatant then washed with $2 \mathrm{ml}$ alkaline salt and saturated chloroform. The washed extract was then shaken with $5 \mathrm{ml}$ heptane and $2.5 \mathrm{ml} 0.1 \mathrm{~N}$ hydrochloric acid. Histamine was measured fluorimetrically in $1 \mathrm{ml}$ of the final acid extract with $0.1 \mathrm{ml}$ OPA for 4 minutes at $450 \mathrm{~nm}$ emission excited at $360 \mathrm{~nm}$.

In another set of experiment Wistar rats were divided in to four groups- normal control group, disease control group, control treated with catechin $(100 \mathrm{mg} / \mathrm{kg})$, disease treated with catechin $(100 \mathrm{mg} / \mathrm{kg})$. Arthritis was induced by sub plantar injection of $0.1 \mathrm{ml}$ of complete Freund's adjuvant (CFA) in left hind paw. ${ }^{10}$ Treatment with the test compounds was started on the day 1 and continued for 21 days. Paw volumes were recorded on the day of injection as well as $5^{\text {th }}$ day and $21^{\text {st }}$ day, whereby paw volume was measured plethysmographically. Physical parameters like body weight, arthritic index, was also measured after experimental period. Blood will be collected from retro orbital plexus for measurement of biochemical and hematological parameters like serum $\mathrm{C}$-reactive protein, serum rheumatoid factor and erythrocyte sedimentation rate as an indicative of inflammation. Body weight measurements were carried out weekly. On day 21, Rats were sacrificed and ankle joints were subjected to histopathological studies.

\section{Statistical analysis}

Values are expressed as mean \pm standard error of the mean. The results were analyzed using one-way factorial analysis of variance followed by Tukey's multiple comparison tests using Graphpad Prism 5 software. The value of $\mathrm{P}$ less than $5 \%(\mathrm{P}<0.05)$ was considered as statistically significant.

\section{Results}

\section{Effect of Catechin on compound 48/80 induced lethality.}

Protective effect of catechin was evaluated in rats by challenging compound 48/80. The results were summarized in Table 1 indicates that fourteen days treatment of catechin to normal rats showed significant $(\mathrm{p}<0.05)$ protection against lethality induced by compound 48/80. Results also showed significant decrease in blood histamine levels dose dependently as compared to normal rats. Similarly dose dependent inhibition of histidine decarboxylase activity as observed in all treatment groups (Table 1).

\section{Effect of catechin on Freund adjuvant induced rheumatoid arthritis}

Effect of Catechin on body weight gain: Animals treated with Freund's adjuvant gained weight more slowly than normal control group. In present study, the weight loss of CFA-injected rats could be reversed by administration of catechin $(100 \mathrm{mg} / \mathrm{kg})$ when compared with disease control group (Table 2).

Table I Effect of catechin on compound $48 / 80$ induced lethality

\begin{tabular}{lllll}
\hline Parameters & NC & CAT-25 & CAT-50 & CAT-100 \\
\hline \% lethality in & 100 & 89 & 66 & 47 \\
Blood histamine content $(\mathrm{ng} / \mathrm{ml})$ & $60.10 \pm 5.11$ & $54.23 \pm 2.53$ & $40.22 \pm 1.94 *$ & $32.06 \pm 3.10^{*}$ \\
Histidine decarboxylase activity $(\mathrm{ng} / \mathrm{ml})$ & $66.58 \pm 2.55$ & $60.30 \pm 3.55$ & $72.62 \pm 3.08^{*}$ & $85.45 \pm 3.22^{*}$ \\
\hline
\end{tabular}

*Significantly different from normal control $(p<0.05)$, each group consists of 6animals. Values are expressed as Mean \pm SEM, NC-normal control, CAT-25 normal animals treated with catechin $(25 \mathrm{mg} / \mathrm{kg} / \mathrm{day}, \mathrm{p.O})$, CAT-50 normal animals treated with catechin $(50 \mathrm{mg} / \mathrm{kg} / \mathrm{day}, \mathrm{p} . \mathrm{o})$, CAT- 100 normal animals treated with catechin $(100 \mathrm{mg} / \mathrm{kg} /$ day,p.o)

Table 2 Effect of catechin on physical parameters

\begin{tabular}{lllll}
\hline Parameters & NC & C-CAT & DC & D-CAT \\
\hline Body weight $(\mathrm{gm})$ & $26.67 \pm 1.66$ & $22.50 \pm \mathrm{I} .1 \mathrm{I}$ & $16.67 \pm 1.05^{*}$ & $22.50 \pm \mathrm{I} .1 \mathrm{I} \#$ \\
Paw volume $(\mathrm{ml})$ & $0.385 \pm 0.09$ & $0.253 \pm 0.05$ & $0.948 \pm 0.15^{*}$ & $0.191 \pm 0.05 \#$ \\
Paw thickness $(\mathrm{cm})$ & $0.253 \pm 0.01$ & $0.210 \pm 0.01 \mathrm{I}$ & $0.406 \pm 0.01 *$ & $0.223 \pm 0.07 \#$ \\
\hline
\end{tabular}

*Significantly different from normal control $(p<0.05)$, \#significantly different from disease control $(p<0.05)$, each group consists of 6 animals.Values are expressed as Mean \pm SEM, NC-normal control, C-CAT-control treated with catechin $(100 \mathrm{mg} / \mathrm{kg} / \mathrm{day}, \mathrm{p} . \mathrm{o}$.), DC- disease control, D-CAT - disease treated with catechin $(100 \mathrm{mg} / \mathrm{kg} /$ day, p.o.) 
Effect of Catechin on arthritic index: Administration of Freund's adjuvant produced significant increase in arthritic index in disease control group as compared to normal control group. An significant reduction in the clinical arthritic index was also observed in the group treated with Catechin (Table 2).

Effect of Catechin on paw volume and paw thickness: Animals exhibited a marked edema of the injected paw, after Freund's adjuvant injection. Administration of Catechin showed significant reduction in paw volume as compared to disease control group. Control treated group did not show any significant change. Thus catechin exhibited notable efficacy in inhibiting the paw edema of the arthritic rats after 21 days treatment (Table 2). As shown in Table 2. Complete freund's adjuvant injected animals exhibited marked increase of paw thickness in disease control groups as compared to normal control group. Control treated group did not show any significant change. Administration of Catechin significantly reduced paw thickness as compared to disease control group.

\section{Effect of catechin on biochemical and hematological parameters}

Effect of catechin on rheumatoid factor: Rheumatoid factor is closely associated with rheumatic diseases. It was observed that in disease control group significant increase in rheumatoid factor was observed as compared to normal control group which was found to be improved by treatment with catechin (Table 3 ).

Table 3 Effect of catechin on biochemical and hematological parameters

\begin{tabular}{|c|c|c|c|c|}
\hline Parameters & NC & C-CAT & DC & D-CAT \\
\hline CRP (mg/dl) & $6.68 \pm 0.18$ & $5.40 \pm 0.21$ & $8.65 \pm 0.32 *$ & $5.66 \pm 0.20 \#$ \\
\hline SRF (IU/ml) & $60.08 \pm 0.40$ & $56.58 \pm 0.59$ & $72.24 \pm 0.82 *$ & $57.02 \pm 1.18 \#$ \\
\hline $\operatorname{ESR}(\mathrm{mm} / \mathrm{h})$ & $4.48 \pm 0.12$ & $4.84 \pm 0.13$ & $7.10 \pm 0.39 *$ & $3.71 \pm 0.19 \#$ \\
\hline
\end{tabular}

*Significantly different from normal control ( $p<0.05)$, \#significantly different from disease control ( $p<0.05)$, each group consists of 6 animals. Values are expressed as Mean \pm SEM, NC-normal control, C-CAT-control treated with catechin (I00mg/kg/day, p.o.), DC- disease control, D-CAT-disease treated with catechin ( $100 \mathrm{mg} / \mathrm{kg} /$ day, p.o.).

Effect of catechin on C-reactive protein and erythrocyte sedimentation rate: Serum C-reactive protein, and ESR are biochemical markers for inflammation. Administration of complete freund's adjuvant raised levels of serum C-reactive protein and ESR in disease control groups as compared to normal control group. Catechin treated group showed significant reduction in all these inflammatory biomarkers (Table 3 ).

\section{Effect of catechin on histopathology of ankle joints}

In histopathology of ankle joints in normal control group showed normal joint structure, no cartilage distruction and no signs of inflammation or other distoration was observed. While in disease treated group mild to moderate hyperplasia of synovium; focal cartilage distruction; infiltration of inflammatory cells, presence of pannus formation with distruction of joint space was observed. Treatment with catechin showed significant improvement in hyperplasia of synovium and reduction in inflammatory cell inflitration as compared to disease treated group (Figure 1).

\section{Discussion}

Histamine is a primary amine synthesized from histidine by enzyme histidine decarboxylase present in mast cell which is an important mediator-secreting cell in allergic diseases. The histidine decarboxylase inhibitors are agent which inhibits the conversion of histidine to histamine, and therefore, it is thought to be beneficial through reduction of potentially damaging, histamine-related local immune response in allergic diseases. ${ }^{11}$ Compound $48 / 48$ is strong mast cell degranulating agent produces release of histamine. ${ }^{12}$ In present study, intraveneous administration of compound 48/48 to rats showed mortality of animals due to release of histamine from mast cells within $4 \mathrm{hrs}$ of administration. Catechin has shown dose dependent inhibition of lethality in rats, indicates its histidine decarboxylase inhibitory activity. Moreover, reduction in blood histamine levels as well as inhibition of histidine decarboxylase activity confirms the mechanism of action of catechine.
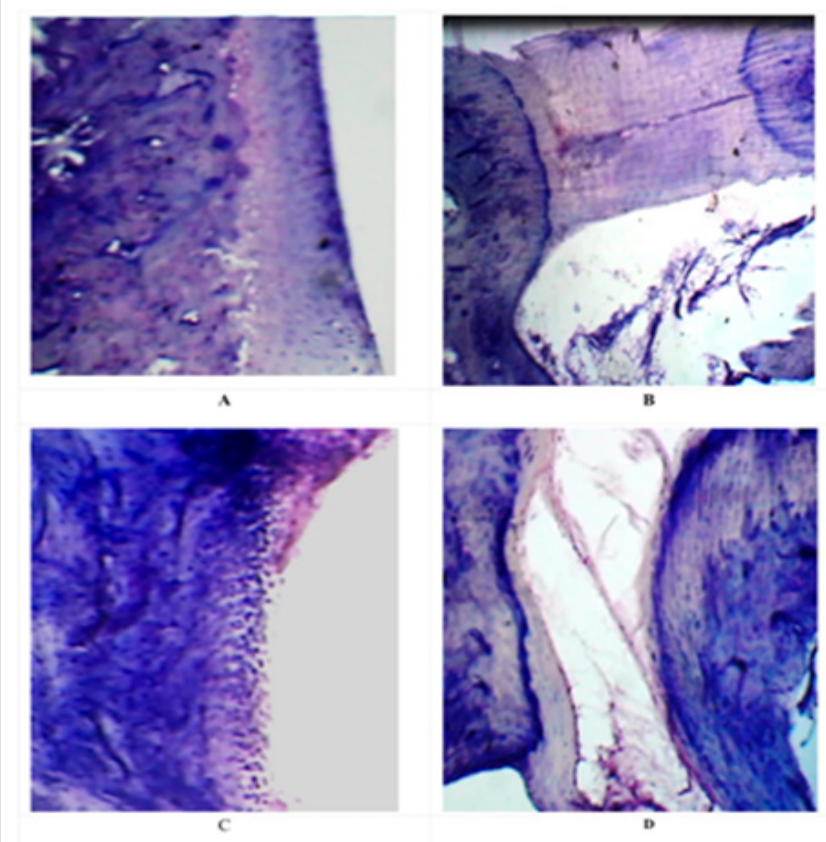

Figure I Effect of Catechin on histopathology of ankle joints. (A) Normal control group, (B) Disease control group; (C) Control treated with catechin, (D) Disease treated with catechin.

Rheumatoid arthritis is a chronic, cytokine-mediated destructive inflammatory polyarticular joint disease, characterized by massive synovial proliferation, systemic and local inflammation resulting in cartilage and bone destruction. Immunologic mechanisms contribute 
to the pathogenesis of rheumatoid arthritis is evidenced serologically by rheumatoid factorsand histologically by presence of lymphocytes, mast cells and macrophages in the rheumatoid synovium. ${ }^{13}$

Complete freund's adjuvant arthritis is an experimental model of polyarthritis which has been widely used for preclinical testing due to reliable onset and progression as well as easily measurable polyarticular inflammation, marked bone resorption. ${ }^{14-16}$ The present study was carried out to see the efficiency of catechin against a chronic inflammatory disease, like arthritis.

In present study during the course of the experimental period body weight loss was observed in diseased rats. Finding from the study by Granado et al., ${ }^{17}$ implicated that with increase in the incidence and severity of arthritis, a decrease in body weights of the rats occurred due to enhanced protein breakdown by the ubiquitin-proteasome proteolytic pathway, or muscle wasting or alterations in the metabolic activities of diseased rats. ${ }^{17,18}$ Treatment has shown protective effect on weight loss in disease control group indicates protection against protein breakdown, muscle wasting due to immunoprotective response produced by catechin.

The determination of paw swelling is apparently simple, sensitive and quick procedure for evaluating the degree of inflammation and assessing of therapeutic effects. In the present study, complete freund's adjuvant administration resulted in increase in paw volume and thickness in rats as compared to normal control rats which is having close similarities to human rheumatoid diseases. ${ }^{19}$ Complete freund's adjuvant induces the initial reaction of edema and soft tissue thickening at the depot site by the irritant effect of the adjuvant, whereas late phase arthritis and flare in the injected foot are presumed to be immunologic events. Treatment with catechin produced statistically significant reduction in paw thickness as well as volume. According to literature review catechin reported to have significant immunologic effect, ${ }^{20}$ supports its use for treatment of autoimmune disorders like rheumatoid arthritis. There is increasing evidence that histidine decarboxylase enzymes play an important role in the synthesis of histamine in mast cells of acute and chronic inflammation..$^{21,22}$ Thus, it can be concluded that chatechin have beneficial effect on inflammatory changes by virtue of inhibition of histamine synthesis.

Arthritic index is characterized by inflammation, formation of nodules. Many reports suggest the pathophysiologic role of histamine in the process of remodeling and joint destruction in rheumatoid arthritis. In chronically affected joints, the synovium develops many villous folds and thickens because of increased numbers and size of infiltrating mast cells and other inflammatory cells which synthesize histamine, interleukin-2, cytokines, rheumatoid factor and other immunoglobulins. ${ }^{23}$ Thus, histamine have a significant role in inflammatory and allergic conditions including arthritis. In our study catechine has shown significant reduction in arthritic index as compared to normal control group. Therefore, possible mechanism for antiarthritic effect of catechin on arthritic index might be suppressive effect on histamine production in mast cell.

The rheumatoid factor is the indicator of involvement of immune system in rheumatoid arthritis. ${ }^{24}$ In present study a significant increase in rheumatoid factor observed in disease control group as compared to normal control group. Recently, synovial mast cells and their effector molecule, histamine, receive increased attention as mediators of joint inflammation. ${ }^{25}$ Treatment with catechine showed decrease in rheumatoid factor. The decrease in rheumatoid factor in rats by treatment with catechin can be linked to its capacity to suppress proliferation of mast calls driven immune responses.

Adjuvant disease shows elevated blood levels of biochemical marker: CRP and ESR. ${ }^{26,27}$ CRP and ESR levels were more closely linked to the rate of disease progression and is a markers for histamine release by mast cells or basophils in inflammatory conditions. ${ }^{28}$ In present study catechin showed significant decrease in CRP and ESR levels indicates reduction in disease progression by catechin by virtue of anti-inflammatory activity associated with histamine synthesis.

Histopathological evaluations of ankle joints of disease control rats showed marked damage of articular structure indicating joint damage and inflammation, hyperplasia of synovium, focal cartilage destruction, and presence of pannus formation. Ankle joints of catechin treated group showed protection against damage of articular structure, inflammation, hyperplasia of synovium, focal cartilage destruction, and pannus formation. In the course of pathogenesis of rheumatoid arthritis, formations of immune complexes activates the immune system and induce degranulation of mast cells, followed by histamine release, which is proven to be indispensable for joint inflammation. ${ }^{29}$ Catechin improved joint inflammation by inhibiting histamine synthesis reflects its functionality in arthritic diseases. ${ }^{30-33}$

\section{Conclusion}

In conclusion, our results strongly indicate that catechin shows beneficial role in rheumatoid arthritis by reduction in paw inflammation, arthritic index, and inflammatory biochemical markers due to the inhibition of histamine syntheis. Therefore, our data suggests that catechin might offer a new therapeutic approach to allergic inflammatory diseases.

\section{Acknowledgments}

The authors would like to acknowledge the funding provided by Nirma University in the form of minor research project.

\section{Conflicts of interest}

The authors state that there are no conflicts of interest pertaining to this manuscript.

\section{Author contributions}

Snehal S. Patel designed and supervised the experiment; Vinit D. Patel has performed the experiments. All authors provided comments on initial and final drafts of the manuscript.

\section{Reference}

1. Lee DM, Friend DS, Gurish MF, et al. Mast cells: a cellular link between autoantibodies and inflammatory arthritis. Science. 2002;297(5587):1689-1692.

2. Silman AJ, MacGregor AJ, Thomson W. Twin concordance rates for rheumatoid arthritis: results from a nationwide study. Br J Rheumatol. 1997:32:903-907.

3. Bogs J, Downey MO, Harvey JS, et al. Proanthocyanidin synthesis and expression of genes encoding leucoanthocyanidin reductase and anthocyanidin reductase in developing grape berries and grapevine leaves. Plant Physiol. 2005;139:652-663. 
4. Jin X, Zheng R, Li Y. Green tea consumption and liver disease: a systematic review: Tea and liver disease. Liver International. 2008;28(7):990-996.

5. Hirasawa M, Takada K. Multiple effects of green tea catechin on the antifungal activity of antimycotics against Candida albicans. $J$ Antimicrob Chemother. 2004;53(2):225-229.

6. Shiozaki T, Sugiyama K, Nakazato K. Effect of tea extracts, catechin and caffeine against type-I allergic reaction. Yakugaku Zasshi. 1997; 117:448-454

7. Suzuki, M, Yoshino K, Maeda-Yamamoto M, et al. Inhibitory effects of tea catechins and O-methylated derivatives of (-)-epigallocatechin-3-Ogallate on mouse type IV allergy. J Agric Food Chem. 2000;48;56495653.

8. Maeda-Yamamoto M,Ema K, Shibuichi I. In vitro and in vivo anti-allergic effects of "benifuuki" green tea containing O-methylated catechin and ginger extract enhancement. Cytotechnology. 2007;55:135-142.

9. Hye MA, Taher MA, Ali MY. Isolation of (+)-Catechin from Acacia Catechu (Cutch Tree) by a Convenient Method. Journal of Scientific Research. 2015;17:41.

10. Fehrenbacher JC, Vasko MR, Duarte DB, et al. Models of Inflammation: Carrageenan- or Complete Freund's Adjuvant (CFA)-Induced Edema and Hypersensitivity in the Rat. In: Enna SJ, Williams M, Barret JF, et al. editors. Current Protocols in Pharmacology. Hoboken, NJ, USA John Wiley \& Sons, Inc; 2012.

11. Nitta Y, Kikuzaki H, Ueno H. Food components inhibiting recombinant human histidine decarboxylase activity. J.Agric Food Chem. 2007;55299-304

12. Chatterjea D, WetzelA, Mack M, et al. Mast cell degranulation mediates compound 48/80-induced hyperalgesia in mice. Biochem Biophys Res Commun. 2012;425(2):237-243.

13. McInnes IB, Schett G. The Pathogenesis of Rheumatoid Arthritis. New England Journal of Medicine. 2008;365:2205-2219.

14. Chillingworth NL, Donaldson LF. Characterisation of a Freund's complete adjuvant-induced model of chronic arthritis in mice. $J$ Neurosci Methods. 2003;128(1-2):45-52.

15. Bhat AS Tandan SK, Kumar D, et al. Interaction between inhibitors of inducible nitric oxide synthase and cyclooxygenase in adjuvantinduced arthritis in female albino rats: an isobolographic study. Eur $J$ Pharmacol. 2007;556(1-3):90-199.

16. Benslay DN, Bendele AM. Development of a rapid screen for detecting and differentiating immunomodulatory vs. anti-inflammatory compounds in rats. Agents Actions. 1991;34(1-2):254-256.

17. Granado M, Priego T, Martín AI, et al. Ghrelin receptor agonist GHRP2 prevents arthritis-induced increase in E3 ubiquitin-ligating enzymes MuRF1 and MAFbx gene expression in skeletal muscle. Am J Physio Endocrinol Metab. 2005;289(6):E1007-1014.
18. Lecker SH. Ubiquitin-protein ligases in muscle wasting: multiple parallel pathways? Curr Opin Clin Nutr Metab Care. 2003;6(3):271275

19. Singh D, Arora V, Sobti PC, Chronic/recurrent cough in rural children in Ludhiana, Punjab. Indian Pediatr. 2002;39:23-29.

20. Maeda-Yamamoto M, Ema K, Monobe M, et al. Epicatechin-3-O-(3"O-methyl)-gallate content in various tea cultivars (Camellia sinensis L.) and its in vitro inhibitory effect on histamine release. J Agric Food Chem. 2012;60(9):2165-2170.

21. Sheng YJ, Bird, J, Florentin, et al. In vivo effects of an acute nonimmunological inflammation in rats on the lymphoproliferative response to mitogens. Int J Immunopharmacol. 1984;6(6):563-567.

22. Yamauchi K. [Regulation of gene expression of L-histidine decarboxylase and histamine N-methyl-transferase, and its relevance to the pathogenesis of bronchial asthma]. Nippon Rinsho. 1996;54(2):377388

23. Tomić-Lucić AP, Pantović SB, Rosić GL, et al. Histamine index and clinical expression of rheumatoid arthritis activity. Vojnosanit Pregl. 2010;67(4):286-290.

24. Dörner T, Hansen A. Autoantibodies in normals--the value of predicting rheumatoid arthritis. Arthritis Res Ther. 2004;6:282-284.

25. Adlesic M, Verdrengh M, Bokarewa M, et al. Histamine in rheumatoid arthritis. Scand J Immunol. 2007;65(6):530-537.

26. Kim KW, Kim BM, Moon HW, et al. Role of C-reactive protein in osteoclastogenesis in rheumatoid arthritis. Arthritis Research \& Therapy. 2015;17.

27. Tall AR. C-reactive protein reassessed. $N$ Engl $J$ Med. 2004;350(14):1450-1452.

28. Lin RY, Trivino MR, Curry A, et al. Interleukin 6 and C-reactive protein levels in patients with acute allergic reactions: an emergency departmentbased study. Ann Allergy Asthma Immunol. 2001;87(5):412-416.

29. Nent E, Frommholz D, Gajda M, et al. Histamine 4 receptor plays an important role in auto-antibody-induced arthritis. Int Immunol. 2013;25(7):437-443.

30. Auclair S, Milenkovic D, Besson C. et al. Catechin reduces atherosclerotic lesion development in apo E-deficient mice: a transcriptomic study. Atherosclerosis. 2009;204(2):e21-27.

31. Tang LQ, Wei W, Wang XY. Effects and mechanisms of catechin for adjuvant arthritis in rats. Advances in Therapy. 2007;24(3):679-690.

32. Takaishi T, Morita Y, Hirai K. Mouse IL-3 induces histamine release from mouse peritoneal mast cells. Int Arch Allergy Immunol. 992;98:205-210. 